\title{
Enhancing liquid-chilled storage and cryopreservation capacities of ram spermatozoa by supplementing the diluent with different additives
}

\author{
Sherif A. Rateb ${ }^{1, *}$, Marwa A. Khalifa', Ibrahim S. Abd El-Hamid', and Hesham A. Shedeed ${ }^{1}$
}

\begin{abstract}
* Corresponding Author: Sherif A. Rateb Tel: +20-0109-731-0306, Fax: +20-2-2635-7858, E-mail: rateb.drc@gmail.com
\end{abstract}

'Animal and Poultry Production Division, Desert Research Center, Ministry of Agriculture and Land Reclamation, Cairo 11753, Egypt

ORCID

Sherif A. Rateb

https://orcid.org/0000-0001-5988-745X

Marwa A. Khalifa

https://orcid.org/0000-0001-7131-4953

Ibrahim S. Abd El-Hamid

https://orcid.org/0000-0002-0369-3004

Hesham A. Shedeed

https://orcid.org/0000-0001-7511-7172

Submitted Apr 18, 2019; Revised Sept 8, 2019; Accepted Sept 30, 2019
Objective: In the present study, we determined efficiency of incorporating caffeine, melatonin or omega-3 polyunsaturated fatty acid in the diluent on mitigating consequences of (a) liquid chilled- and (b) cryo-storage of ram spermatozoa.

Methods: In the first experiment, ejaculates $(n=30)$ were collected from 5 adult rams and were pooled, diluted (1:10) with Tris-citric acid (base diluent) and were split into 4 aliquots assigned for: control (untreated), caffeine $(0.1 \mathrm{mM})$, melatonin $(0.3 \mathrm{mM})$ or omega-3 fatty acids $(0.3 \mathrm{mM})\left(\mathrm{T}_{0}\right)$. The diluted specimens were stored at $4^{\circ} \mathrm{C}$ for $48 \mathrm{~h}$, during which sperm physical and cytological properties were evaluated along with oxidative stress indices $\left(\mathrm{T}_{24}\right.$, $\mathrm{T}_{48}$ ). In the second experiment, 15 ejaculates ( 3 per male) were pooled, diluted with glycerolized base diluent ( $4 \%$ glycerol, v/v) and were split corresponding to the same previous treatment groups before being processed for cryopreservation. Post-thaw physical and kinematic sperm properties were assessed by a computer-assisted sperm analysis system.

Results: The results clarified superiority of both melatonin and omega-3 supplementation on maintaining $(\mathrm{p}<0.05)$ sperm properties, while reducing $(\mathrm{p}<0.05)$ lipid peroxidase reaction and enzymatic activities of alanine aminotransferase, aspartate aminotransferase, and alkaline phosphatase in preservation medium, compared to caffeine either during liquid-chilled storage or cryopreservation of spermatozoa.

Conclusion: Melatonin and omega-3 are regarded efficient alternatives to caffeine when processing ram spermatozoa for application of artificial insemination or in vitro fertilization.

Keywords: Cryopreservation; Oxidative Stress; Computer-assisted Sperm Analysis (CASA); Ram Semen

\section{INTRODUCTION}

Extensive application of sophisticated reproductive techniques played a vital role in improving livestock industry in recent years. Artificial insemination (AI) and in vitro fertilization (IVF) are among the most applicable techniques utilized to achieve this goal in large domestic animals. In sheep, however, successful application of such technologies is still lacking although it is essentially required to develop breeds with superior productivity, resistant against diseases, or high capacity to cope with harsh environmental conditions [1]. Consequently, developing sperm processing procedures, to maintain sperm physical properties and fertilization potential, became a prerequisite for successful application of these techniques.

Liquid-chilled storage is considered most appropriate for sperm preservation when semen is required within a short period of time after collection for AI or IVF [2]. However, the full potential of semen utilization, mostly in commercial application schemes, relies 
on cryopreserved doses [3]. Nonetheless, both sperm preservation techniques have detrimental effects on physical and morphometric properties of spermatozoa and, hence, on sperm fertilizing capacity [4].

Sheep sperm cell membranes contain higher amounts of polyunsaturated fatty acids (PUFAs) than in other species [5]. Therefore, ram spermatozoa are highly susceptible to the oxidative damage that occurs during chilled storage [6] or freezing/thawing cycle of semen [7].

Primarily, the seminal fluid contains a wide spectrum of endogenous enzymatic and non-enzymatic antioxidants that act as free radical scavengers to protect spermatozoa [8]. However, the protective effects of such naturally-existed antioxidants decrease due to dilution of semen for processing [9]. Therefore, studies on inclusion of different antioxidants in sperm preservation medium became in focus of recent fertilityrelated practices. In vitro supplementation of melatonin [10], caffeine [11] and n-3 PUFAs [12] in the diluent have been reported to improve sperm preservation capacity in buffalos, rams and cow bulls, respectively. However, the degree of improvement varied dramatically among the studies due to species differences, as well as level and type of the supplement.

In the current study, two experiments were conducted to evaluate influence of incorporating melatonin, caffeine or omega-3 PUFAs in the diluent on ameliorating the oxidative stress occurring during liquid chilled and cryo-preservation of ram spermatozoa.

\section{MATERIALS AND METHODS}

\section{Ethics statement}

All procedures were conducted conforming to the ISO 9001: 2015 quality management regulations and were approved by the Animal Care and Use Committee of Desert Research Center, Egypt, complying with the guidelines and regulations of the Animal Ethics Committee Institute of the European Parliament for protection of experimental animals (2010/63/EU).

\section{Animals}

This investigation was implemented at the Artificial Insemination Lab., Mariout Research Station (Latitude $31^{\circ} 00^{\prime} \mathrm{N}$; Longitude $29^{\circ} 47^{\prime} \mathrm{E}$ ), Desert Research Center, Egypt. Five sexually mature Barki rams aged 36 to 48 months, and an average body weight of $45.0 \pm 2.0 \mathrm{~kg}$, were used during April, 2017 . All rams were housed in a fenced stockyard throughout the period of the study, and were allowed a daily grazing period from 0800 to $1400 \mathrm{~h}$. Thereafter, they were fed a concentrate mixture according to their protein and energy requirements [13]. Egyptian clover, Trifolium alexandrinum, hay was provided ad libitum, and fresh water was presented once daily after returning from the pasture. Before executing the experiment, all rams were clinically examined and were found free of disease or reproductive disorders.

\section{Liquid-chilled storage medium (base diluent)}

A Tris-citric acid egg yolk base diluent was prepared for liquidchilled storage of ram spermatozoa as previously reported [14]. The diluent was clarified from egg yolk particles by centrifugation at 2,400 $\mathrm{g}$ for $15 \mathrm{~min}$ and aspiration of the clear supernatant. The clarified base diluent was prepared $24 \mathrm{~h}$ prior to each collection session and was stored at $4^{\circ} \mathrm{C}$ until use.

\section{Semen collection}

Semen was collected 3 times weekly at $0700 \mathrm{~h}$ by an artificial vagina. Collection tubes with modified plastic water jackets were used to maintain the ejaculates at $37^{\circ} \mathrm{C}$ during the collection sessions. Soon after collection, each raw ejaculate was transported to the laboratory, directly adjacent to the collection area, and was immediately evaluated for sperm physical and morphometric traits.

\section{Raw ejaculates assessment and pooling}

The raw ejaculates were kept in a warm water bath adjusted at $37^{\circ} \mathrm{C}$ throughout the assessment. Ejaculate volume $(\mathrm{mL})$ was recorded using the graded collection tubes. The $\mathrm{pH}$, sperm concentration $\left(\times 10^{6} / \mathrm{mL}\right)$, mass motility score $(5=$ highly motile, $0=$ immotile), progressive motility (\%), viability (\%), normal sperm (\%), and intact acrosome (\%) were also analyzed for each raw ejaculate. Accordingly, adequate ejaculates of each collection session from the same rams were pooled. Mean values of the aforementioned criteria in raw-pooled ejaculates, throughout the period of the study, are displayed in Table 1.

\section{Experimental design}

Effects on oxidative status and liquid-chilled storage capacity of spermatozoa: In this experiment, 30 ejaculates were obtained from the 5 rams, 6 ejaculates each, and ejaculates of each collection session were pooled and diluted (1:10) with the clarified base diluent. The diluted specimens were further split into 4 aliquots. The first aliquot served as control (un-

Table 1. Physical and morphometric properties of raw ram ejaculates (mean \pm standard error of the mean)

\begin{tabular}{lc}
\hline Parameter & \\
\hline Volume $(\mathrm{mL})$ & $0.80 \pm 0.04$ \\
$\mathrm{pH}$ & $7.2 \pm 0.1$ \\
Sperm concentration $\left(\times 10^{6} / \mathrm{mL}\right)$ & $2,335.6 \pm 22.5$ \\
Mass motility score $(5-0)^{1)}$ & $4.28 \pm 0.06$ \\
Progressive motility (\%) & $92.5 \pm 0.6$ \\
Live sperm (\%) & $89.9 \pm 1.2$ \\
Normal sperm (\%) & $90.5 \pm 0.6$ \\
Intact acrosome $(\%)$ & $90.1 \pm 0.9$ \\
\hline
\end{tabular}

1) Mass motility score: 5 , highly motile; 0 , immotile. 
treated), whereas the other three aliquots were supplemented either with $0.1 \mathrm{mM}$ caffeine (1,3,7-trimethylxanthine, SigmaAldrich, Shanghai, China, Cat. no. 1001176428) [15], $0.3 \mathrm{mM}$ melatonin (N-Acetyl-5-methoxytryptamine, Sigma-Aldrich, St. Louis, MO, USA; Cat. no. M5250) [16] or $0.3 \mathrm{mM}$ omega-3 PUFAs (Trimegavitals, Modern Health Lab. LLC, Berdsk, Russia) [14]. The later adjunct consisted of $52.6 \%$ eicosapentaenoic acid (1.65 mmol/L EPA, 20:5 n-3), 26.3\% docosahexaenoic acid $(0.76 \mathrm{mmol} / \mathrm{L}$ DHA, 22:6 $n$-3) and $21.1 \%$ a-linolenic acid $(0.72 \mathrm{mmol} / \mathrm{L}$ ALA, $18: 3 n-3)$. The omega- 3 oil was emulsified in the egg yolk-containing base diluent and was vortexed for $2 \mathrm{~min}$ prior to the dilution process assuring that the oil was properly mixed with the medium. Immediately after dilution $\left(\mathrm{T}_{0}\right)$ all specimens were transported to a cooling cabinet $\left(4^{\circ} \mathrm{C}\right)$ and were stored for $48 \mathrm{~h}$, during which sperm physical and morphometric properties were evaluated along with oxidative stress indices at $24 \mathrm{~h}$ interval $\left(\mathrm{T}_{24}, \mathrm{~T}_{48}\right)$.

\section{Semen assessment}

Total sperm motility (\%) was evaluated using a phase-contrast microscope (Leica Inc., Wetzlar, Germany) at $40 \times$ magnification, whereas viability was assessed by eosin-nigrosin differential staining technique at 1,000× magnification. Romanowski's triple-stain method (DIFF-QUICK III, Vertex, Cairo, Egypt) was used to evaluate primary and secondary sperm abnormalities, as well as acrosomal cap integrity. Smears preparation and staining processes were performed as per the manufacturer's instructions, and stained smears were evaluated by a phase-contrast microscope at $1,000 \times$ magnification. The functional integrity of sperm plasma membrane was determined by the hypo-osmotic swelling (HOS) test [17], where at least 200 sperm were evaluated at $40 \times$ magnification.

\section{Determination of oxidative stress indices and enzymatic activities}

A portion of each semen group $(2 \mathrm{~mL})$ was aspirated and centrifuged (1,000 $\mathrm{g}$ for $10 \mathrm{~min})$ at times parallel to those of sperm assessment $\left(\mathrm{T}_{0}, \mathrm{~T}_{24}\right.$, and $\left.\mathrm{T}_{48}\right)$. The aspirated supernatant was stored at $-20^{\circ} \mathrm{C}$ until oxidative stress indices and enzymatic activities were analyzed. The changes in total antioxidant capacity (TAC), malondialdehyde acetate (MDA) concentration, reduction of the resazurin dye test (RRT) and alkaline phosphatase (ALP) activity were analyzed by colorimetric kits (Biodiagnostic, Cairo, Egypt). Alanine aminotransferase (ALT) and aspartate aminotransferase (AST) concentrations were analyzed colorimetrically by kits obtained from Spectrum, Egypt. All procedures were conducted according to the manufacturers' instructions.

\section{Effects on cryopreservation capacity of ram spermatozoa} Cryopreservation medium and semen processing: After centrifugation and clarification as illustrated previously, the base diluent was supplemented with $2 \%$ glycerol at $37^{\circ} \mathrm{C}$, and was split into 4 aliquots representing the same previously mentioned additives. Another fifteen ejaculates were collected from the same 5 rams, in 3 collection sessions, and, similar to that of experiment 1 , ejaculates of each collection session were pooled and diluted (1:10) with the glycerolized base diluent (portion- $\mathrm{A}, \mathrm{T}_{0}$ ). All specimens were equilibrated for $3 \mathrm{~h}$ at $4^{\circ} \mathrm{C}$. Thereafter, a second aliquot of chilled-glycerolized diluent (portion- $\mathrm{B}, \mathrm{T}_{3}$ ) was added to portion-A to reach a final concentration of $4 \%$ glycerol in whole medium. Afterwards, the specimens were equilibrated for another $2 \mathrm{~h}$ at $4^{\circ} \mathrm{C}\left(\mathrm{T}_{5}\right)$ before being packed in $0.5 \mathrm{~mm}$ French straws $\left(200 \times 10^{6}\right.$ sperm/ straw) using a mini-tübe filling and sealing machine (Model 133, Mini-tübe, Germany). The straws were placed in a minitübe biological freezer, and were exposed to nitrogen vapor $\left(-80^{\circ} \mathrm{C}\right)$ for $10 \mathrm{~min}$ before being immersed in liquid nitrogen. The frozen straws were stored under liquid nitrogen surface $\left(-196^{\circ} \mathrm{C}\right)$ until physical and kinematic properties of spermatozoa were analyzed by a computer-assisted sperm analysis (CASA) system.

\section{Computer-assisted sperm analysis}

The frozen straws (5 per group) were thawed in a programmable thawing device (Mini-tübe GmbH, Tiefenbach, Germany) adjusted at $38^{\circ} \mathrm{C}$ for 40 seconds. Immediately after thawing, each sample was evaluated for sperm physical and kinematic criteria using a computer-assisted sperm analysis system (Mira-9000, Mira Lab, Cairo, Egypt). The system was designed to follow the world health organization strict criteria of human semen [18]. Prior to assessment, the system was calibrated for normal ram sperm morphometric properties and motility pattern. A minimum of 200 sperm, from 10 random bright fields, was evaluated at 500 $\times$ magnification for total sperm motility (\%), rapid (Class-A) and regular (Class-B) progressive motility (\%), non-progressive motility (Class-C, \%), immotile sperm (Class-D, \%) and viability (\%). Sperm kinematics in terms of straight line velocity (VSL, $\mu \mathrm{m} / \mathrm{s}$ ), curvilinear velocity (VCL, $\mu \mathrm{m} / \mathrm{s}$ ), average path velocity (VAP, $\mu \mathrm{m} / \mathrm{s}$ ), amplitude of lateral head displacement $(\mathrm{ALH}, \mu \mathrm{m})$, wobble movement coefficient (WOB, \%), linearity (LIN, \%), and straightness (STR, \%) were also assessed.

\section{Statistical analyses}

The data was checked by Shapiro-Wilk's test and were found fitting the normal distribution. Mean values of pooled (raw) sperm properties were obtained by simple t-test. The changes in the same sperm criteria, as well as oxidative stress indices and enzymatic activities, in liquid-chilled specimens were analyzed by repeated measures analysis of variance (ANOVA) where the fixed effects of treatment, time $\left(\mathrm{T}_{0}, \mathrm{~T}_{24}\right.$, and $\left.\mathrm{T}_{48}\right)$ and treatment by time interaction were determined. Furthermore, one-way ANOVA (F test) was used to compare CASA- 
derived physical and kinematic sperm properties among control and treated groups. The statistical significance threshold was set at $5 \%$ and the differences between means were detected by Tukey's post-hoc test. The data were analyzed using IBM-SPSS statistics program for windows [19]. The results are expressed as means \pm standard error of mean.

\section{RESULTS}

\section{Effects on liquid-chilled storage capacity of ram spermatozoa}

The results showed that the percent of progressive motility decreased $(\mathrm{p}<0.05)$ over time of storage in all groups. However, at $\mathrm{T}_{48}$, both melatonin- and omega 3- supplemented groups recorded the highest $(\mathrm{p}<0.05)$ values of progressive motility (\%) compared to control and caffeine-supplemented specimens (Table 2). A similar trend was also observed in both percentages of live and normal spermatozoa (Table 2). On the other hand, no significant difference was observed in the percent of primary sperm abnormalities among control and treated groups over the storage period. However, the percent of secondary sperm abnormalities were higher $(p<0.05)$ in control and caffeine-supplemented groups at T48 compared to melatonin- and omega 3-supplemented groups (Table 2). It is worth mentioning that the observed secondary abnor- malities comprised presence of distal/translocating cytoplasmic droplets with subsequent tail opening and/or defective tails (bent, folded, or coiled tails). Contrarily, at $\mathrm{T}_{48}$ of storage, the intact acrosome percent was significantly lower $(\mathrm{p}<0.05)$ in control and caffeine-treated groups, compared to those supplemented with melatonin or omega 3 . In the meantime, the control group recorded the lowest $(\mathrm{p}<0.05)$ percent of intact sperm cell membrane, as determined by HOS test, compared to all supplemented groups (Table 2).

\section{Effects on oxidative status during $48 \mathrm{~h}$ of liquid-chilled storage}

The levels of TAC in preservation medium decreased significantly $(\mathrm{p}<0.05)$ in both control and caffeine-treated semen over time of storage, reaching the lowest $(\mathrm{p}<0.05)$ values at T48 compared to other supplemented specimens (Table 3 ). Contrariwise, MDA concentration increased $(\mathrm{p}<0.05)$ in the control group and reached the highest $(\mathrm{p}<0.05)$ level at $\mathrm{T}_{48}$ compared to all treated groups (Table 3). No significant difference was observed in reduction of RRT among control and treated specimens over time of storage (Table 3). On the other hand, enzymatic activities of ALT, AST, and ALP in preservation medium increased significantly $(\mathrm{p}<0.05)$ in the control group over the $48 \mathrm{~h}$ preservation period recording the highest $(\mathrm{p}<0.05)$ activities at $\mathrm{T}_{48}$ compared to all treated specimens

Table 2. Effect of supplementing sperm preservation medium with different additives on physical and morphometric properties of ram spermatozoa during $48 \mathrm{~h}$ of liquidchilled storage at $4^{\circ} \mathrm{C}$ (mean \pm standard error of the mean)

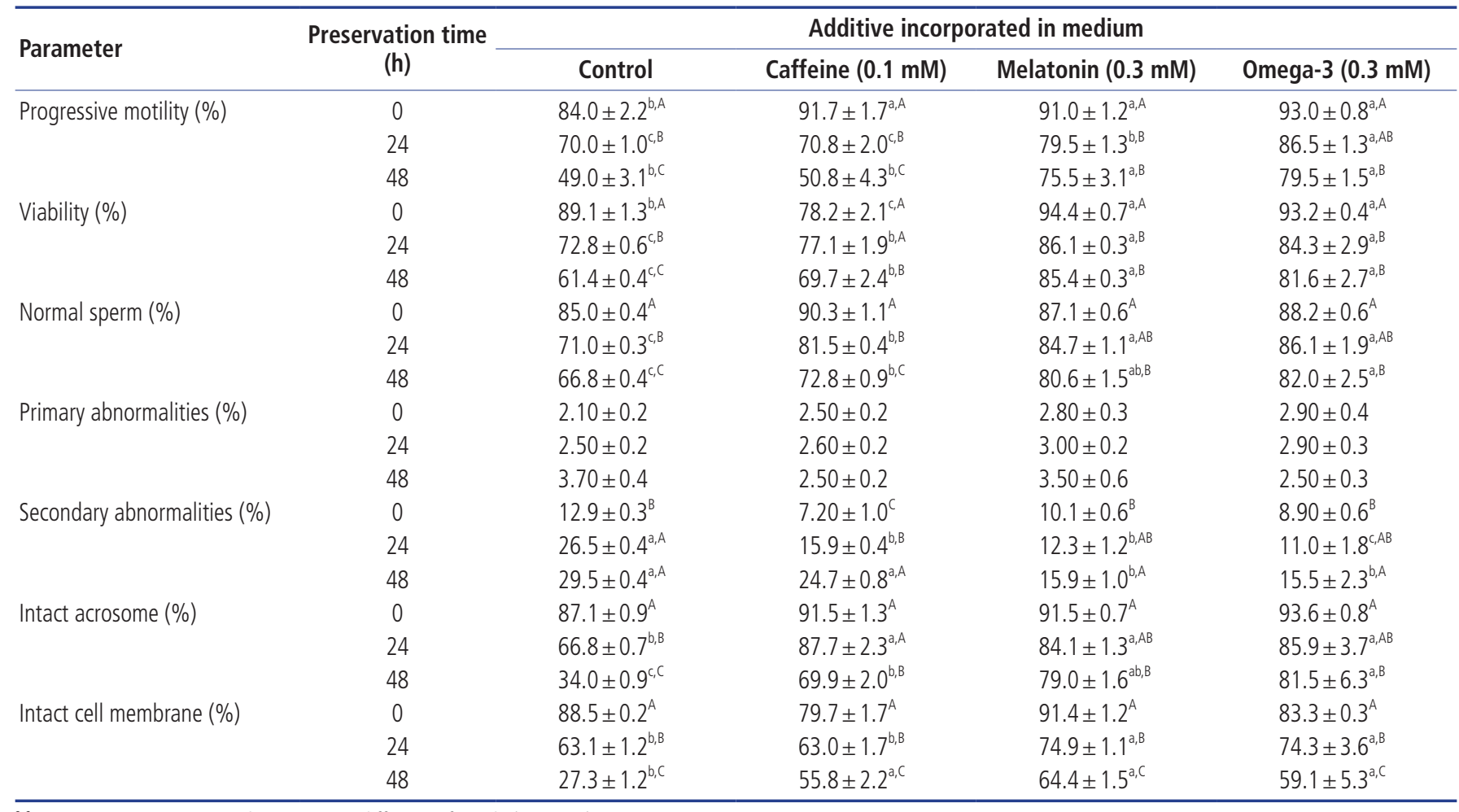

\footnotetext{
a-c Letters among groups in the same row differ significantly $(p<0.05)$.

A-C Letters in the same column within each parameter differ significantly $(p<0.05)$.
} 
Table 3. Influence of incorporating different additives into ram sperm diluent on oxidative stress indices and enzymatic activities during $48 \mathrm{~h}$ of liquid-chilled storage at $4^{\circ} \mathrm{C}$ (mean \pm standard error of the mean)

\begin{tabular}{|c|c|c|c|c|c|}
\hline \multirow{2}{*}{ Parameter } & \multirow{2}{*}{$\begin{array}{l}\text { Preservation time } \\
\text { (h) }\end{array}$} & \multicolumn{4}{|c|}{ Additive incorporated in medium } \\
\hline & & Control & Caffeine (0.1 mM) & Melatonin (0.3 mM) & Omega-3 (0.3 mM) \\
\hline \multirow[t]{3}{*}{ TAC (mM/L) } & 0 & $0.68 \pm 0.1^{\mathrm{a}, \mathrm{A}}$ & $0.53 \pm 0.1^{b}$ & $0.58 \pm 0.1^{\mathrm{ab}}$ & $0.64 \pm 0.1^{\mathrm{a}}$ \\
\hline & 24 & $0.48 \pm 0.1^{\mathrm{ab}, \mathrm{B}}$ & $0.31 \pm 0.1^{b}$ & $0.52 \pm 0.1^{\mathrm{ab}}$ & $0.64 \pm 0.1^{\mathrm{a}}$ \\
\hline & 48 & $0.38 \pm 0.1^{b, B}$ & $0.36 \pm 0.1^{b}$ & $0.64 \pm 0.2^{\mathrm{a}}$ & $0.66 \pm 0.1^{\mathrm{a}}$ \\
\hline \multirow[t]{3}{*}{$\mathrm{MDA}(\mathrm{nM} / \mathrm{L})$} & 0 & $17.1 \pm 1.1^{B}$ & $15.1 \pm 1.0$ & $17.9 \pm 1.1$ & $16.0 \pm 1.0$ \\
\hline & 24 & $18.7 \pm 1.8^{B}$ & $15.3 \pm 0.4$ & $15.3 \pm 2.1$ & $16.2 \pm 0.9$ \\
\hline & 48 & $26.1 \pm 2.3^{\mathrm{a}, \mathrm{A}}$ & $15.3 \pm 0.7^{b}$ & $12.9 \pm 0.5^{b}$ & $15.1 \pm 1.3^{b}$ \\
\hline \multirow[t]{3}{*}{ RRT } & 0 & $2.50 \pm 0.6$ & $2.70 \pm 0.4$ & $2.40 \pm 0.9$ & $2.00 \pm 0.8$ \\
\hline & 24 & $2.50 \pm 0.6$ & $2.60 \pm 0.6$ & $2.50 \pm 0.5$ & $2.00 \pm 0.9$ \\
\hline & 48 & $2.60 \pm 0.6$ & $2.40 \pm 0.6$ & $2.60 \pm 0.5$ & $2.10 \pm 0.6$ \\
\hline \multirow[t]{3}{*}{ ALT (U/L) } & 0 & $94.90 \pm 2.5^{B}$ & $92.7 \pm 1.3$ & $94.6 \pm 2.7$ & $88.1 \pm 3.5$ \\
\hline & 24 & $103.3 \pm 1.9^{\mathrm{a}, \mathrm{A}}$ & $91.2 \pm 2.2^{\mathrm{ab}}$ & $87.4 \pm 1.4^{\mathrm{ab}}$ & $78.5 \pm 1.5^{b}$ \\
\hline & 48 & $102.1 \pm 3.6^{\mathrm{a}, \mathrm{A}}$ & $93.6 \pm 2.6^{\mathrm{ab}}$ & $86.0 \pm 1.4^{b c}$ & $78.9 \pm 3.5^{c}$ \\
\hline \multirow[t]{3}{*}{ AST (U/L) } & 0 & $230.6 \pm 6.9$ & $232.1 \pm 3.2$ & $222.3 \pm 9.7$ & $223.8 \pm 5.4$ \\
\hline & 24 & $246.7 \pm 5.6^{\mathrm{a}}$ & $238.4 \pm 3.5^{b}$ & $230.7 \pm 2.5^{b}$ & $230.3 \pm 6.1^{b}$ \\
\hline & 48 & $261.5 \pm 6.8^{\mathrm{a}}$ & $238.9 \pm 6.3^{b}$ & $230.2 \pm 2.6^{b}$ & $236.2 \pm 4.1^{b}$ \\
\hline \multirow[t]{3}{*}{$\mathrm{ALP}(\mathrm{IU} / \mathrm{L})$} & 0 & $243.4 \pm 3.9^{B}$ & $239.9 \pm 9.8^{B}$ & $246.1 \pm 4.8$ & $242.1 \pm 3.5$ \\
\hline & 24 & $252.9 \pm 3.7^{\mathrm{A}}$ & $251.1 \pm 6.2^{A}$ & $242.2 \pm 2.6$ & $246.1 \pm 9.4$ \\
\hline & 48 & $263.9 \pm 3.6^{\mathrm{a}, \mathrm{A}}$ & $253.7 \pm 3.1^{b, A}$ & $245.3 \pm 4.2^{b c}$ & $240.6 \pm 9.3^{c}$ \\
\hline
\end{tabular}

TAC, total antioxidant capacity; MDA, malondialdehyde acetate; RRT, reduction of resazurin dye test; ALT, alanine aminotransferase; AST, aspartate aminotransferase; ALP, alkaline phosphatase.

a-c Values in the same row with different superscript letters differ significantly $(p<0.05)$.

$A, B$ Values in the same column with different superscript letters differ significantly $(p<0.05)$.

(Table 3).

\section{Effects on post-thaw physical and kinematic sperm properties}

The CASA-derived assessment revealed that the omega 3treated specimens recorded the highest $(\mathrm{p}<0.05)$ post-thaw progressive motility (\%), whereas the control group recorded the lowest $(\mathrm{p}<0.05)$ value (Figure 1$)$. Meanwhile, the control group showed the lowest $(\mathrm{p}<0.05)$ percentages of sperm viability and normal spermatozoa compared to each of caffeine-, melatonin- and omega 3- treated groups (Figure 1). Even though no significant difference was observed in post-thaw primary abnormalities among control and treated groups, the percent of secondary sperm abnormalities was significantly higher $(\mathrm{p}<0.05)$ in the control group compared to all other treated specimens (Figure 1). Similarly, the results showed that the percent of intact acrosome was significantly lower $(\mathrm{p}<0.05)$ in the control group compared to all other treatments (Figure 1). Concurrently, both control and caffeinesupplemented groups exhibited the lowest $(\mathrm{p}<0.05)$ percentages of integrated cell membrane compared to melatonin- and omega 3- supplemented groups (Figure 1).

The results of post-thaw sperm kinematics showed that inclusion of the three additives in cryopreservation medium affected $(\mathrm{p}<0.05)$ all sperm motion and velocity patterns except for motion indices of LIN (\%) and STR (\%) (Figure 2).
In this regard, the percent of post-thaw progressive motility, particularly those of class-A and $B$, was higher $(\mathrm{p}<0.05)$ in both melatonin- and omega 3-supplemented groups compared to those of control and caffeine-supplemented specimens. Furthermore, the melatonin- supplemented group exhibited the highest $(p<0.05)$ percent of non-progressive motility and $\operatorname{VAP}(\mu \mathrm{m} / \mathrm{s})$, while recording the lowest $(\mathrm{p}<0.05)$ percent of immotile spermatozoa compared to all other groups (Figure $2)$. On the other side, values of ALH $(\mu \mathrm{m})$ were significantly higher $(\mathrm{p}<0.05)$ in the omega-3 group $(2.7 \pm 0.2 \mu \mathrm{m})$ than those observed in control $(1.8 \pm 0.3 \mu \mathrm{m})$ and caffeine-supplemented group $(1.6 \pm 0.2 \mu \mathrm{m})$. In addition, the results demonstrated an improvement $(\mathrm{p}<0.05)$ in VCL $(\mu \mathrm{m} / \mathrm{s})$ and VSL $(\mu \mathrm{m} / \mathrm{s})$ in all supplemented specimens compared to that of control (Figure 2).

\section{DISCUSSION}

Exposing spermatozoa to cold-shock through chilled storage or cryopreservation alters their cell membrane structure and function due to spontaneous lipid peroxidase reaction (LPO) and increased MDA production. These alterations comprise redistribution of membrane bound phospholipids and proteins as well as membrane permeability and ion exchange [20], which decrease sperm viability and fertility [21] and, eventually, cause sperm death [22]. Ram spermatozoa, having high 

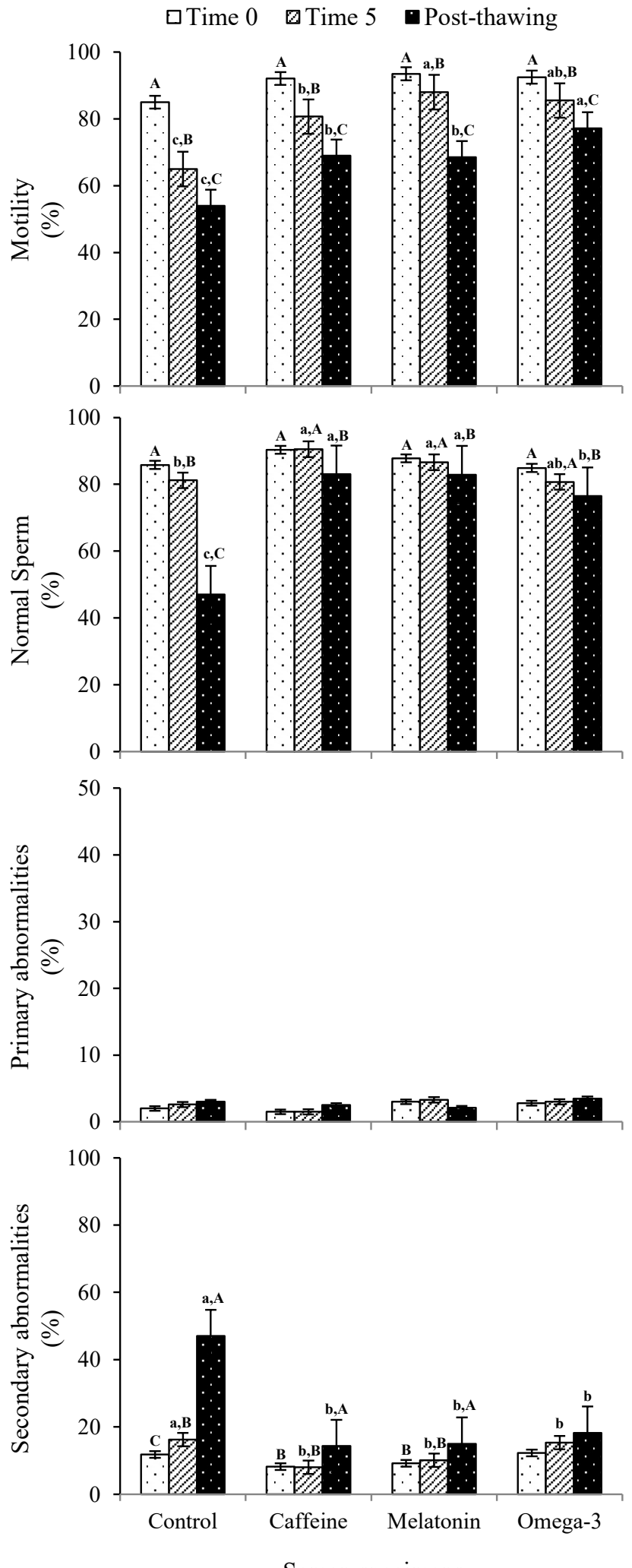
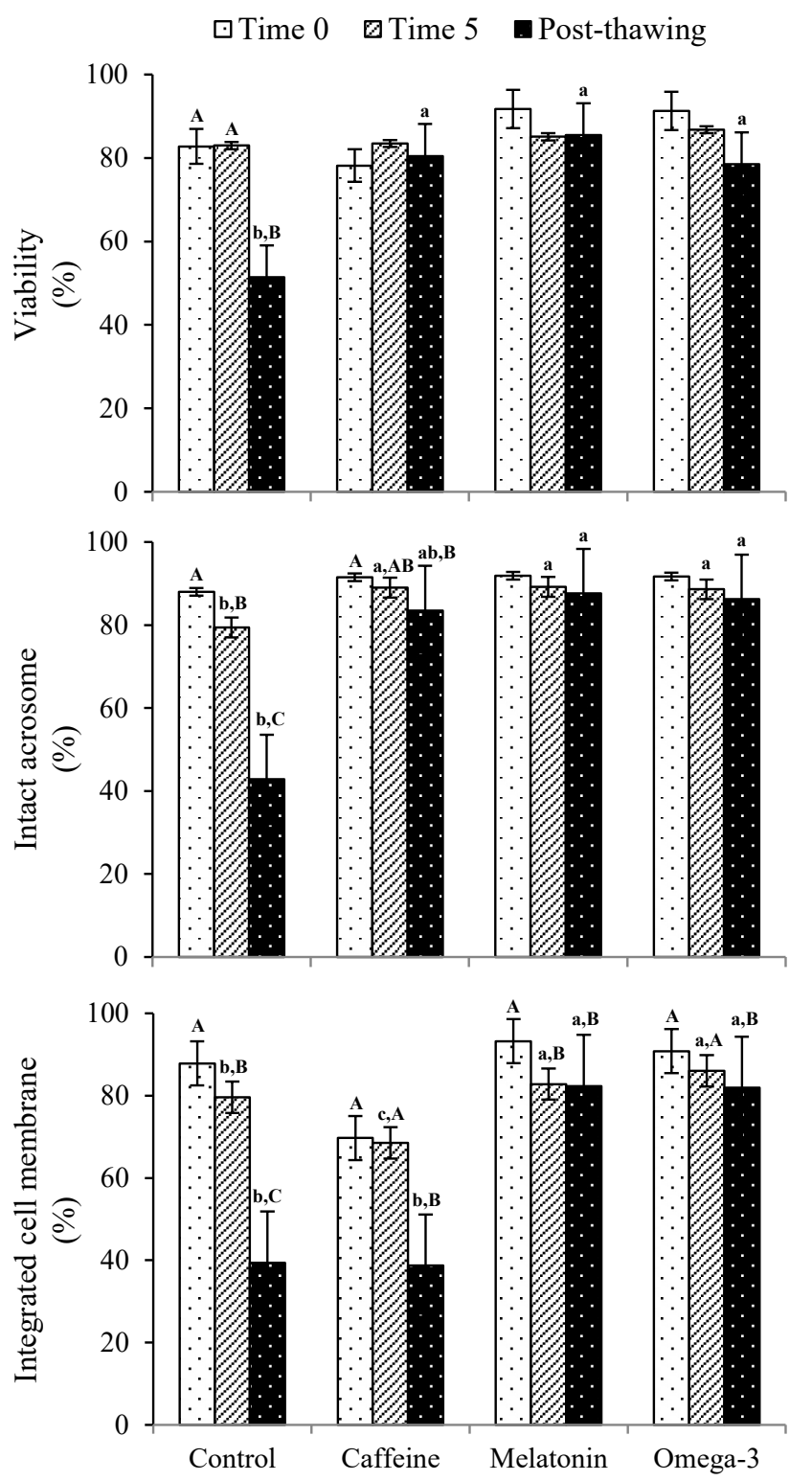

Semen specimens

Figure 1. Cryosurvival characteristics of ram spermatozoa after supplementing preservation medium with different additives (mean \pm standard error of the mean). Control, untreated; Caffeine, medium was supplemented with $0.1 \mathrm{mM}$ caffeine; Melatonin, medium was supplemented with $0.3 \mathrm{mM}$ melatonin; Omega-3, medium was supplemented with $0.3 \mathrm{mM}$ omega-3 polyunsaturated fatty acids (i.e. eicosapentaenoic acid [20:5 n-3], docosahexaenoic acid [22:6 n-3], and a-linolenic acid [18:3 n-3]). a-c Letters among groups differ significantly $(p<0.05)$. ${ }^{A-C}$ Letters within each supplement differ significantly $(p<0.05)$. 


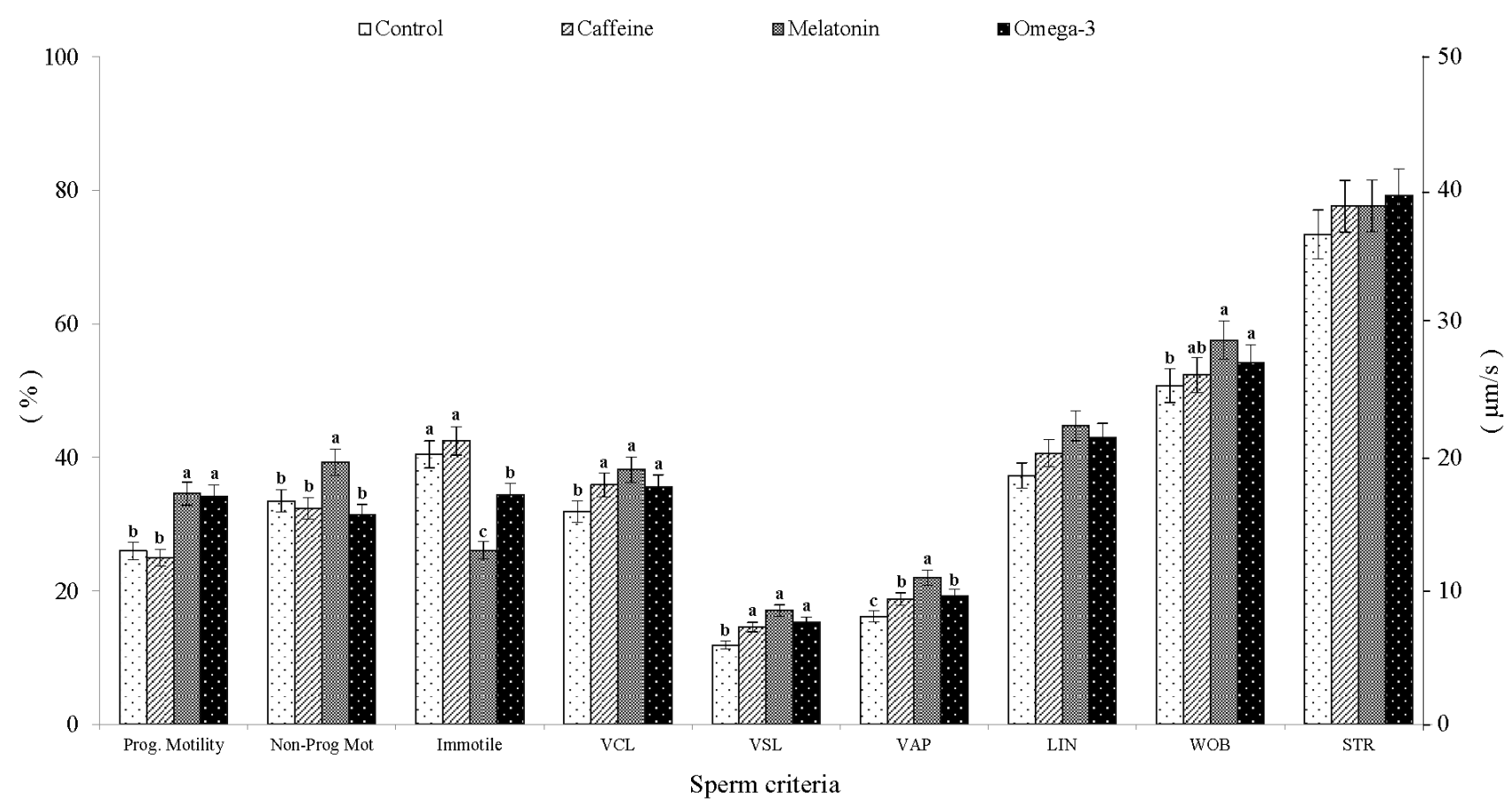

Figure 2. Computer-assisted sperm analysis (CASA)-derived analysis for post-thaw kinematics and velocity pattern of ram spermatozoa after supplementing cryopreservation medium with different additives (mean \pm standard error of the mean). Prog. Motility, progressive motility (Class-A and B, \%); Non-prog mot, nonprogressive motility (Class-C, \%); Immotile, (Class-D, \%); VCL, curvilinear velocity $(\mu \mathrm{m} / \mathrm{s})$; VSL, straight-line velocity ( $\mu \mathrm{m} / \mathrm{s})$; VAP, average path velocity $(\mu \mathrm{m} / \mathrm{s}) ; \mathrm{ALH}$, amplitude of lateral head displacement $(\mu \mathrm{m})$; LIN, linearity (VSL/VCL, \%); WOB, wobble movement coefficient (VAP/NCL, \%); STR, straightness (VSL/VAP, \%). Control, untreated; Caffeine, medium was supplemented with $0.1 \mathrm{mM}$ caffeine; Melatonin, medium was supplemented with $0.3 \mathrm{mM}$ melatonin; Omega-3, medium was supplemented with 0.3 mM omega-3 polyunsaturated fatty acids (i.e. eicosapentaenoic acid [20:5 n-3], docosahexaenoic acid [22:6 $n$-3], and $\alpha$-linolenic acid [18:3 $n-3]$ ). ${ }^{\text {acc }}$ Letters among groups differ significantly $(p<0.05)$.

concentration of PUFAs in their cell membranes, are exceptionally vulnerable to such stress with subsequent reduced sperm motility and loss of sperm functional integrity during chilled- or cryo- preservation $[2,5]$.

The present results clarified that caffeine supplementation drastically reduced sperm motility and increased secondary morphological abnormalities over chilled-preservation time compared to both melatonin and omega-3. This was combined with decreased TAC and elevated LPO and enzymatic activities in caffeine-treated specimens compared to the other treated groups. Furthermore, although incorporating caffeine into cryopreservation medium increased VCL, VSL, VAP, LIN, and WOB compared to melatonin- and omega 3-treated specimens, it negatively affected integrity of sperm cell membranes. This is in consonance with previous results in rams [23]. Contrariwise, improved sperm acrosome integrity has been reported after caffeine inclusion in sperm diluent of buffalos [24] and camels [25].

Caffeine (1,3,7-trimethylxanthine) is a natural stimulant belonging to the methylxanthine class, and has been utilized as a supplement in sperm capacitation medium to enhance progressive motility in IVF schemes. Caffeine inhibits cyclic nucleotide phosphodiesterase resulting in increased intracellular cyclic adenosine monophosphate. The later acts directly on sperm plasma membrane channels to increase intracellular calcium ions in sperm flagella and induces immediate sperm hyper-activation [11]. Hyper-activation is commonly observed in spermatozoa undergoing capacitation [26], which may explain the increased levels of altered acrosome/cell membranes observed in caffeine-treated specimens, particularly those subjected to liquid-chilled storage, in the current investigation. Furthermore, sperm hyper-activation implies the high energy state of spermatozoa. This was reflected in the increased sperm kinematic criteria observed in caffeine-treated specimens in the present results. Such increase in sperm kinematics could be attributed to ability of caffeine to activate glycogen phosphorylase and consequent glycogen breakdown into simple sugars [27], available for consumption by spermatozoa to cope with stimulated motility.

On the other side, our results clarified the antioxidant capabilities of melatonin supplementation on counteracting detrimental effects of LPO reaction on chilled- and cryopreserved spermatozoa. In addition to its multiple actions on different physiological processes, melatonin and its metabolites are considered powerful antioxidants due to their ability to scavenge excessive ROS and, thus, protect spermatozoa [28]. Furthermore, melatonin has the potency to improve mitochondrial health state and functions via modulating glu- 
tathione activity thereby improving IVF outcomes [10].

The results also demonstrated the protective effects of omega-3 PUFAs on maintaining sperm physical properties and functional integrity during both liquid-chilled and cryostorage. These results are in accordance with those reported previously in rams [14]. Omega-3 comprises a group of essential long chain PUFAs that influence biosynthetic pathways involved in regulation of animals' various functions including reproduc $\neg$ tion. The EPA, DHA, and ALA are considered the 3 major $n$-3 PUFAs that target reproductive cells and alter reproductive function and fertility [29]. These $n$-3 PUFAs act directly on sperm membrane lipid composition to promote creation of microdomains with different flexibility, fluidity, fusogenicity, and permeability characteristics, hence, they were regarded as the major determinants of sperm mobility characteristics, cold sensitivity, viability and membrane integrity [30]. Moreover, they provide spermatozoa with energy and regulate membrane proteins thereby maintaining sperm viability during exposure to cold stress [31].

In summary, our results accentuated potency of both melatonin and omega-3 PUFAs when incorporated into chilledand cryo-preservation medium on ameliorating the deleterious effects of oxidative stress and, consequently, maintaining sperm physical and kinematic properties compared to caffeine supplementation. Further studies are still needed to declare the effects of inclusion of these additives in sperm preservation medium on AI and IVF outcomes.

\section{CONFLICT OF INTEREST}

We certify that there is no conflict of interest with any financial organization regarding the material discussed in the manuscript.

\section{ACKNOWLEDGMENTS}

The authors are grateful to Prof. K. El-Bahrawy for providing the melatonin, and to Prof. M. Al-Dequen and all the staff of Al-Andalos Medical Lab. for providing all the facilities to perform the CASA analysis.

\section{REFERENCES}

1. Baldassare H, Karatzas CN. Advanced assisted reproduction technologies (ART) in goats. Anim Reprod Sci 2004;82-83: 255-66. https://doi.org/10.1016/j.anireprosci.2004.04.027

2. Câmara DR, Mello-Pinto MMC, Pinto LC, Brasil OO, Nunes JF, Guerra MMP. Effects of reduced glutathione and catalase on the kinematics and membrane functionality of sperm during liquid storage of ram semen. Small Rumin Res 2011; 100:44-9. https://doi.org/10.1016/j.smallrumres.2011.05.010

3. Faigl V, Vass N, Jávor A, et al. Artificial insemination of small ruminants - a review. Acta Vet Hung 2012;60:115-29. https:// doi.org/10.1556/AVet.2012.010

4. Peña FJ, Rodríguez-Martinez H, Tapia JA, Ortega Ferrusola C, Gonzalez Fernández L, Macías García B. Mitochondria in mammalian sperm physiology and pathology: a review. Reprod Domest Anim 2009;44:345-9. h https://doi.org/10. 1111/j.1439-0531.2008.01211.x

5. Ashrafi I, Kohram H, Naijian H, Bahreini M, Poorhamdollah M. Protective effect of melatonin on sperm motility parameters on liquid storage of ram semen at $5^{\circ} \mathrm{C}$. Afr J Biotechnol 2011; 10:6670-4.

6. Agarwal A, Saleh RA, Bedaiwy MA. Role of reactive oxygen species in the pathophysiology of human reproduction. Fertil Steril 2003;79:829-43. https://doi.org/10.1016/S0015-0282(02) 04948-8

7. Alvarez JG, Storey BT. Differential incorporation of fatty acids into and peroxidative loss of fatty acids from phospholipids of human spermatozoa. Mol Reprod Dev 1995;42:334-46. https://doi.org/10.1002/mrd.1080420311

8. Soren S, Singh SV, Singh P. Influence of season on seminal antioxidant enzymes in Karan Fries bulls under tropical climatic conditions. Turk J Vet Anim Sci 2016;40:797-802. https:// doi.org/10.3906/vet-1603-76

9. Mostafa T, Anis T, Imam H, El-Nashar AR, Osman IA. Seminal reactive oxygen species-antioxidant relationship in fertile males with and without varicocele. Andrologia 2009;41:125-9. https:// doi.org/10.1111/j.1439-0272.2008.00900.x

10.El-Raey MR, Badr R, Darwish GM. Evidences for the role of melatonin as a Protective additive during buffalo semen freezing. Am J Anim Vet Sci 2014;9:252-62. https://doi.org/10. 3844/ajavsp.2014.252.262

11.El-Shahat KH, Taysser MI, Badr MR, Zaki KA. Effect of heparin, caffeine and calcium ionophore A23187 on in vitro induction of the acrosome reaction of fresh ram spermatozoa. Asian Pac J Reprod 2016;5:148-55. https://doi.org/10.1016/ j.apjr.2016.01.012

12. Kaka A, Wahid H, Rosnina Y, et al. Alpha-linolenic acid supplementation in tris extender can improve frozen-thawed bull semen quality. Reprod Domest Anim 2015;50:29-33. https:// doi.org/10.1111/rda.12445

13. NRC, National Research Council of the National Academies. Nutrient requirement of small ruminants: sheep, goats, cervids, and new world camelids. Washington DC, USA: National Academies Press; 2007. https://doi.org/10.17226/11654

14. Rateb SA. Influence of omega-3 incorporation in sperm preservation medium on physical and kinematic properties of chilled and cryopreserved ram spermatozoa. Reprod Domest Anim 2018;53:1506-16. https://doi.org/10.1111/rda.13289

15. Abd El-Hamid IS. Effect of adding different levels of caffeine in the extender on some biochemical constituents, enzymatic activities and physical characteristics of chilled and frozen ram semen. Reprod Domest Anim 2019;54:225-33. https:// 
doi.org/10.1111/rda.13339

16. Khalifa MA. Improving cryopreservation capacity of ram spermatozoa by supplementing the diluent with melatonin. Int J Anim Res 2017;1:17. https://doi.org/10.28933/ijar-2017-110202

17. Mosaferi S, Niasari-Naslaji A, Abarghani A, Gharahdaghi AA, Gerami A. Biophysical and biochemical characteristics of bactrian camel semen collected by artificial vagina. Theriogenology 2005;63:92-101. https://doi.org/10.1016/j.therio genology.2004.03.021

18. WHO. Laboratory manual for the examination and processing of human semen. 5th ed., Geneva, Switzerlad: WHO press; 2010 [cited 2019 Apr]. Available from: https://www.who.int/ reproductivehealth/publications/infertility/978924 1547789/ en/

19.IBM Corp. IBM SPSS Statistics for Windows, Version 22.0. Armonk, NY, USA: IBM Corp., 2013.

20.Lessard C, Parent S, Leclerc P, Baileys JL, Sullivan Jr R. Cryopreservation alters the levels of the bull sperm surface protein P25b. J Androl 2000;21:700-7. https://doi.org/10.1002/j.19394640.2000.tb02138.x

21. Wongtawan T, Saravia F, Wallgren M, Caballero I, RodriguezMartinez H. Fertility after deep intra-uterine artificial insemination of concentrated low-volume boar semen doses. Theriogenology 2006;65:773-87. https://doi.org/10.1016/j.therio genology.2005.07.003

22. Bailey JL, Morrie A, Cormier N. Semen cryopreservation: successes and persistent problems in farm species. Can J Anim Sci 2003;83:393-401. https://doi.org/10.4141/A03-024

23. Špaleková EA, Makarevich V, Kubovičová E, Ostró A, Chrenek P. Effect of caffeine on functions of cooling-stored ram sperm in vitro. Acta Vet Brno 2014;83:19-25. https://doi.org/10.2754/ avb201483010019
24. Shukla MK, Misra AK. Caffeine as a semen additive to improve Murrah buffalo (Bubalus bubalis) semen cryopreservation. Buffalo Bulletin 2014;33:32-6.

25.El-Bahrawy KA. The influence of caffeine supplementation and concerted utilization of enzymatic and mechanical semen liquefaction on freezability of dromedary camel spermatozoa. Int J Vet Sci Med 2017;5:121-7. https://doi.org/10.1016/j.ijvsm. 2017.09.005

26.Suarez SS. Control of hyperactivation in sperm. Hum Reprod Update 2008;14:647-57. https://doi.org/10.1093/humupd/ dmn029

27.Singh P, Raina VS. Effect of caffeine, cAMP and cattle seminal plasma on freezability of buffalo bull semen. Asian-Australas J Anim Sci 2000;13:901-5. https://doi.org/10.5713/ajas.2000. 901

28. Kang JT, Koo OJ, Kwon DK, et al. Effects of melatonin on in vitro maturation of porcine oocyte and expression of melatonin receptor RNA in cumulus and granulosa cells. J Pineal Res 2009;46:22-8. https://doi.org/10.1111/j.1600-079X.2008.00 602. $\mathrm{x}$

29. Thatcher WW, Staples RC. Using fats and fatty acids to enhance reproductive performance. In: Proceeding of the 5th MidAtlantic Nutrition Conference; 2007 Mar 28-29: Timonium, MD, USA. University of Maryland; 2007. pp. 116-29.

30. Robinson JJ, Ashworth CJ, Rooke JA, Mitchell LM, McEvoy TG. Nutrition and fertility in ruminant livestock. Anim Feed Sci Technol 2006;126:259-76. https://doi.org/10.1016/j.ani feedsci.2005.08.006

31. Kiernan M, Fahey AG, Fair S. The effect of the in vitro supplementation of exogenous long-chain fatty acids on bovine sperm cell function. Reprod Fertil Dev 2012;25:947-54. https:// doi.org/10.1071/RD12204 